\title{
Estudo de viabilidade econômica do uso de mictório seco
}

\author{
Economic feasibility study of the use of waterless urinal \\ Estudio de viabilidad económica del uso de urinario seco
}

Recebido: 18/01/2022 | Revisado: 22/01/2022 | Aceito: 29/01/2022 | Publicado: 30/01/2022

\author{
Matheus Vieira Carvalho \\ ORCID: https://orcid.org/0000-0002-3246-6871 \\ Universidade Federal da Paraíba, Brasil \\ E-mail: m.vieira.c.199@gmail.com \\ Lucas Barros Figueiredo de Morais \\ ORCID: https://orcid.org/0000-0002-5019-3184 \\ Universidade Federal da Paraíba, Brasil \\ E-mail: lucasbfm21@gmail.com \\ Cindy Deina Farto \\ ORCID: https://orcid.org/0000-0002-3092-092X \\ Universidade Federal da Paraíba, Brasil \\ E-mail: cindydeina2012@gmail.com \\ Gilson Barbosa Athayde Junior \\ ORCID: https://orcid.org/0000-0003-2815-7600 \\ Universidade Federal da Paraíba, Brasil \\ E-mail: gilson@ct.ufpb.br
}

\begin{abstract}
Resumo
É inegável que a escassez hídrica vem causando racionamentos em alguns grandes centros urbanos brasileiros. Visto isso, a utilização de aparelhos economizadores de água surge como uma das alternativas para a conservação e uso eficiente desse recurso, dentre eles, destacam-se os mictórios secos, que, apesar dos custos de aquisição e de operação, trazem o benefício da economia de água. Este artigo propôs analisar a viabilidade econômica do uso de mictórios secos, para um tempo de vida útil de projeto de 20 anos, com dados referentes ao município de João Pessoa - PB, comparando-os com três tipos de aparelhos sanitários: mictório convencional (cenário 1), bacia sanitária de acionamento duplo (cenário 2) e bacia sanitária de acionamento único (cenário 3). $\mathrm{Na}$ categoria residencial, a utilização do mictório seco não foi analisada para o cenário 1, enquanto, no cenário 2, a viabilidade ocorre a partir de 20 usos diários para a tarifação intermediária e 7 usos diários para a tarifa de residências de padrão alto. Já no cenário 3, a viabilidade é verificada a partir de 7, 4 e 3 usos diários para as tarifas de padrão popular, médio e alto, respectivamente. Nas categorias comercial, industrial e pública, os mictórios secos mostram-se viáveis economicamente nos cenários em que substituem as bacias sanitárias. No cenário 2, os números de usos diários para que ocorra a viabilidade econômica foram a partir de 5, 4 e 4, no cenário 3,2, 2 e 2 para as categorias comercial, industrial e pública, respectivamente.
\end{abstract}

Palavras-chave: Mictório seco; Viabilidade econômica; Uso racional da água.

\begin{abstract}
It is undeniable that water scarcity has been causing rationing in some large Brazilian urban centres. In view of that, the use of water-saving appliances appears as one of the alternatives for the conservation and efficient use of this resource, among them, the waterless urinals stand out, because they bring the savings benefit of water, despite the acquisition and operating costs. This article proposed to analyse the economic feasibility of the use of waterless urinal, for a project lifetime of 20 years, with data referring to the city of João Pessoa - PB (Brazil), comparing them with three types of sanitary appliances: conventional urinal (scenario 1), double-acting sanitary basin (scenario 2) and sanitary basin of single drive (scenario 3). For the residential category, the use of the waterless urinal was not analyzed for scenario 1 , while in scenario 2, viability occurs above 20 daily uses for the intermediate charging and 7 daily uses for the highest value tariff. In scenario 3, viability is verified above 7, 4 and 3 daily uses for popular, average and high standard rate, respectively. For the commercial, industrial and public categories, the waterless urinals are economically viable in the scenarios that they replace the sanitary basins. In scenario 2 , the numbers of daily uses for economic viability to occur are above 5, 4 and 4, and in scenario 3,2, 2 and 2 for the commercial, industrial and public categories, respectively.
\end{abstract}

Keywords: Waterless urinal; Economic feasibility; Rational use of water.

\section{Resumen}

Es innegable que la escasez de agua ha estado causando racionamiento en algunos grandes centros urbanos brasileños. Ante esto, el uso de electrodomésticos ahorradores de agua surge como una de las alternativas para la conservación y 
uso eficiente de este recurso, entre ellos, destacan los urinarios secos, que, a pesar de los costos de adquisición y operación, traen el beneficio del ahorro de agua. Este artículo propuso analizar la viabilidad económica del uso de urinarios secos, para una vida útil del proyecto de 20 años, con datos referidos al municipio de João Pessoa - PB, comparándolos con tres tipos de aparatos sanitarios: urinario convencional (escenario 1), cuenca sanitaria de doble accionamiento (escenario 2) y cuenca sanitaria de accionamiento único (escenario 3). En la categoría residencial, no se analizó el uso del urinario seco para el escenario 1, mientras que, en el escenario 2, la viabilidad se produce a partir de 20 usos diarios para la carga intermedia y 7 usos diarios para la tarifa domiciliaria estándar alta. En el escenario 3 , la viabilidad se verifica a partir de 7, 4 y 3 usos diarios para las tarifas estándar populares, medias y altas, respectivamente. En las categorías comercial, industrial y pública, los urinarios secos son económicamente viables en los escenarios en los que sustituyen a las cuencas sanitarias. En el escenario 2, el número de usos diarios para la viabilidad económica ocurrieron fueron de 5, 4 y 4, en el escenario 3, 2, 2 y 2 para las categorías comercial, industrial y pública, respectivamente.

Palabras clave: Urinario seco; Viabilidad económica; Uso racional del agua.

\section{Introdução}

Permite-se afirmar que a escassez hídrica é um problema relacionado às necessidades básicas dos seres humanos, influenciando direta e negativamente o desenvolvimento econômico e social de um país ou região. Atualmente, constata-se a presença desse problema em alguns municípios do Brasil, cujo abastecimento de água está ameaçado tanto pela quantidade, quanto pela qualidade desse recurso. As crises de abastecimento de água estão se tornando cada vez mais frequentes em determinados locais devido ao crescimento populacional, à falta de gerenciamento adequado dos recursos hídricos, à poluição dos mananciais, às mudanças de hábitos de consumo da população e aos longos períodos de estiagem (Gonçalves, 2006; Jiménez Cisneros et al., 2014; Venancio et al., 2015).

Nesse contexto, o uso racional da água deve ser incentivado pelos poderes públicos e praticado pela população, consistindo assim em ações que podem ser de detecção e combate a vazamentos, utilização de fontes alternativas e uso de aparelhos economizadores de água (Fernandes et al., 2013; Marins \& Moura, 2015). Estes últimos são equipamentos e acessórios hidráulicos que apresentam uma maior eficiência no uso da água quando comparados aos aparelhos convencionais (Hafner, 2007; Sampaio et al., 2019). Os exemplos mais conhecidos dos mesmos são os redutores de vazão, aeradores em torneiras, válvula de descarga com duplo acionamento e mictórios com válvula hidromecânica de fechamento automático.

Como uma alternativa mais eficiente, tem-se utilizado, nos EUA e na Europa, os mictórios que não utilizam água (Gonçalves, 2006). Estes possuem um sistema interno, evitando que o mau cheiro retorne ao ambiente e não havendo a proliferação de bactérias. Já no Brasil, o uso desse aparelho sanitário não é comum e, portanto, os estudos nesta área podem contribuir para a disseminação de sua utilização. Além de benefícios ambientais, por não utilizar nenhum volume de água em seu funcionamento, os mictórios secos podem trazer benefícios econômicos, posto que, com o aumento da escassez da água, o custo desse recurso tem se tornado cada vez maior.

Estima-se que a substituição de aparelhos sanitários convencionais por mictórios secos pode representar uma economia per capita de 2 a 26 m³/ano de água (Medeiros et al., 2021). Em um estudo realizado na Cidade do Cabo, Chipako e Randall (2019) concluíram que o uso desses aparelhos em uma universidade sul-africana resultaria em uma economia anual de cerca de 17,6 mil m³ de água, assumindo-se que os mesmos serão lavados três vezes por dia. Além disso, Bristow et al. (2006) destacam que, por não utilizarem água, o uso dos mictórios secos representa também uma economia com as despesas relacionadas a reparos e substituições de válvulas de descargas, limpeza e entupimentos.

Outro ponto favorável à utilização dos mictórios secos é a sua capacidade de separar a urina, que contém nutrientes essenciais à agricultura, como nitrogênio, fósforo e potássio, coletada dos sistemas de coleta de esgotos. Com isso, há a possibilidade de arrecadação financeira com a venda de fertilizantes produzidos a partir da urina humana. No estudo de caso realizado na Universidade da Cidade do Cabo, por exemplo, Chipako e Randall (2019) concluíram que havia um potencial de produzir 6,7 toneladas de adubo gerado a partir da urina coletada dos mictórios secos, enquanto a instituição requeria 3,6 
toneladas para adubar seus campos de esportes.

Deste modo, este artigo propôs-se a analisar a viabilidade econômica do uso de mictórios secos em comparação a outros três tipos de aparelhos sanitários: mictório convencional, bacia sanitária de acionamento duplo e bacia sanitária de acionamento único. Além disso, realizou-se análises econômicas para quatro tipos de categorias: residencial, comercial, industrial e pública, sendo que, na primeira, considerou-se as três diferentes tarifações cobradas pela concessionária de abastecimento de água do município de João Pessoa - PB.

\section{Metodologia}

A presente pesquisa apoia-se em um estudo de caso acoplada a uma pesquisa de campo para coleta de informações de custos acerca das instalações necessárias para implantação de mictórios secos. É de cunho exploratório-descritivo (Gil, 2007) e do tipo quantitativa (Richardson, 2017).

Para o desenvolvimento do artigo, adotou-se um tempo de vida útil de projeto de 20 anos, valor usualmente utilizado para estruturas hidrossanitárias, e um modelo de mictório seco do tipo com cartucho de gel selante, fabricado no Brasil. Considerou-se uma utilização de quatro vezes diárias deste aparelho sanitário por usuário e as análises econômicas foram realizadas para três tipos cenários diferentes.

\subsection{Cenários adotados}

Este estudo foi divido em três cenários, nos quais, o mictório seco foi comparado a um tipo de acessório sanitário distinto. No primeiro cenário, considerou-se a substituição do mictório convencional pelo mictório seco, enquanto no segundo, a substituição foi da bacia sanitária com caixa acoplada de duplo acionamento (3 ou $6 \mathrm{~L}$ ) e, no terceiro, foi da bacia sanitária de caixa acoplada de acionamento único $(6 \mathrm{~L})$.

\subsubsection{Cenário 1}

No primeiro cenário, considerou-se a substituição do mictório convencional de válvula hidromecânica pelo mictório seco, em que, os custos de instalação foram os de substituição do equipamento e desativação do ponto de água. Apenas para esta análise, julgou-se que já havia o ponto de esgoto instalado previamente, vindo da utilização do mictório convencional, e que o mesmo será reaproveitado para o novo mictório, com exceção da categoria residencial, em que se considerou a não existência do mictório convencional. O consumo médio deste aparelho a ser substituído, segundo o Manual de gerenciamento para controladores de consumo de água da Companhia de Saneamento Básico do Estado de São Paulo (2009), é de cerca de 1,0 L por uso.

\subsubsection{Cenário 2}

Para este cenário, comparou-se os ganhos financeiros em decorrência da economia de água devido à utilização do mictório seco em substituição à bacia sanitária de caixa acoplada de duplo acionamento. Nos custos envolvidos, além da aquisição do produto, foram considerados os de instalação de um ponto de esgoto e do próprio mictório. O volume economizado seria de cerca de 3 litros a cada utilização, o necessário para uma descarga de urina, segundo os fabricantes desse tipo de bacia sanitária. Foi adotado que, a cada uso do mictório seco, seja economizada uma descarga na bacia sanitária.

\subsubsection{Cenário 3}

No último cenário, analisou-se a viabilidade econômica na utilização de um mictório seco ao invés de uma bacia sanitária de caixa acoplada de acionamento único. Semelhantemente ao cenário 2, os custos de instalação considerados são os 
mesmos, enquanto a quantidade de água economizada pelo uso do mictório seco seria de cerca de 6 litros por descarga, volume máximo estabelecido pelo Programa Setorial da Qualidade de Louças Sanitárias para sistemas prediais (Ministério das Cidades, 2004 apud Silva, 2004).

\subsection{Categorias adotadas}

Além dos cenários, fez-se necessário a divisão em categorias, acompanhando a tabela tarifária praticada pela concessionária dos serviços de água local, devido à diferença de valores cobrados. Com isso, realizou-se estudos de viabilidade econômica para as categorias residencial, comercial, industrial e pública. Destaca-se que, na categoria residencial, há tarifas escalonadas por faixa de consumo e, dessa forma, analisou-se a viabilidade para cada uma delas. Além disso, na análise econômica do cenário 1, não se considerou a pré-existência de ponto de esgoto de mictório, pois não é comum se utilizar este dispositivo em residências.

\subsection{Taxa Mínima de Atratividade (TMA)}

A Taxa Mínima de Atratividade (TMA) foi calculada através da média anual da taxa básica de juros (Selic) acumulada ao longo dos últimos noves anos, entre 2012 e 2020. O valor médio encontrado foi de $8,96 \%$ ao ano, conforme exposto na Tabela 1.

Tabela 1 - Taxa média anual da Selic dos últimos nove anos no Brasil.

\begin{tabular}{c|ccccccccc|c}
\hline Anos & 2012 & 2013 & 2014 & 2015 & 2016 & 2017 & 2018 & 2019 & 2020 & Média \\
\hline Selic (\%) & 8,62 & 8,29 & 10,96 & 13,47 & 14,18 & 10,11 & 6,58 & 6,03 & 2,88 & 8,96 \\
\hline
\end{tabular}

Fonte: ADVFN (2021).

\subsection{Custos de implantação}

Os custos de implantação para utilização do mictório seco são compostos pela aquisição do produto, frete e instalação do mictório e do ponto de esgoto. Em um site de um fabricante, é possível fazer a compra do mictório seco e acrescentar o valor do frete. $\mathrm{O}$ valor do modelo mais barato e disponibilizado escolhido para este estudo foi de $\mathrm{R} \$ 569,00$, com o serviço de entrega orçado em $\mathrm{R}$ \$218,90 para a cidade de João Pessoa. Vale ressaltar que o valor do frete pode variar a depender do destino final onde o produto será entregue no estado da Paraíba e, portanto, os valores dos indicadores de viabilidade econômica podem ser alterados.

Já os valores da mão-de-obra para a instalação do mictório e do ponto de esgoto foram obtidos através de pesquisa de mercado com profissionais locais. O custo médio da primeira foi de $\mathrm{R} \$ 34,88$ e, da segunda, $\mathrm{R} \$ 93,01$. Quanto ao custo dos materiais do ponto de esgoto, utilizou-se a tabela de composições dos sistemas de orçamento de obras do estado de Sergipe e esse valor foi de aproximadamente $\mathrm{R} \$ 69,76$.

\subsection{Custos de operação}

Os custos de operação dos mictórios secos são referentes ao recipiente que acondiciona o refil do gel selante, o cartucho. Esse produto tem funcionalidade adequada até uma frequência de 7.500 usos desse aparelho sanitário. De acordo com as pesquisas de mercado realizadas, o valor mais barato desse cartucho é de $\mathrm{R} \$ 222,87$, o que resulta em uma despesa de menos de R \$ 0,03 por uso para a cidade de João Pessoa - PB. 


\subsection{Benefícios econômicos}

A quantidade de água economizada anualmente, devido à utilização do mictório seco, é o principal benefício econômico considerado. Com isso, tomou-se, como referência, os valores das tarifas por metro cúbico de água fornecida pela concessionária local, conforme descrito na Tabela 2. Cabe-se destacar que, para um consumo mensal de até $10 \mathrm{~m}^{3}$, a concessionária dos serviços de água local cobra uma taxa fixa às economias, enquanto para o excedente, a cobrança é proporcional ao consumo. Observa-se ainda o escalonamento da tarifa por faixa de consumo na categoria residencial.

Tabela 2 - Estrutura tarifária da CAGEPA por economia.

\begin{tabular}{c|ccc|c}
\hline Faixa de consumo $\left(\mathbf{m}^{\mathbf{3}} / \mathbf{m e ̂ s}\right)$ & Água & Esgoto & Esgoto $(\%)$ & Total \\
\hline Até 10 (Social) & $\mathrm{R} \$ 10,56$ & $\mathrm{R} \$ 1,06$ & 10 & $\mathrm{R} \$ 11,62$ \\
Até 10 (Residencial) & $\mathrm{R} \$ 40,64$ & $\mathrm{R} \$ 32,51$ & 80 & $\mathrm{R} \$ 73,15$ \\
Até 10 (Comercial) & $\mathrm{R} \$ 72,51$ & $\mathrm{R} \$ 65,26$ & 90 & $\mathrm{R} \$ 137,77$ \\
Até 10 (Industrial) & $\mathrm{R} \$ 87,83$ & $\mathrm{R} \$ 79,05$ & 90 & $\mathrm{R} \$ 166,88$ \\
Até 10 (Pública) & $\mathrm{R} \$ 82,35$ & $\mathrm{R} \$ 82,35$ & 100 & $\mathrm{R} \$ 164,70$ \\
Entre 10 e 20 (Residencial) & $\mathrm{R} \$ 5,24 / \mathrm{m}^{3}$ & $\mathrm{R} \$ 4,19 / \mathrm{m}^{3}$ & 80 & $\mathrm{R} \$ 9,43 / \mathrm{m}^{3}$ \\
Entre 20 e 30 (Residencial) & $\mathrm{R} \$ 6,91 / \mathrm{m}^{3}$ & $\mathrm{R} \$ 6,22 / \mathrm{m}^{3}$ & 90 & $\mathrm{R} \$ 13,13 / \mathrm{m}^{3}$ \\
Mais de 30 (Residencial) & $\mathrm{R} \$ 9,39 / \mathrm{m}^{3}$ & $\mathrm{R} \$ 9,39 / \mathrm{m}^{3}$ & 100 & $\mathrm{R} \$ 18,78 / \mathrm{m}^{3}$ \\
Mais de 10 (Comercial) & $\mathrm{R} \$ 12,56 / \mathrm{m}^{3}$ & $\mathrm{R} \$ 12,56 / \mathrm{m}^{3}$ & 100 & $\mathrm{R} \$ 25,12 / \mathrm{m}^{3}$ \\
Mais de 10 (Industrial) & $\mathrm{R} \$ 13,99 / \mathrm{m}^{3}$ & $\mathrm{R} \$ 13,99 / \mathrm{m}^{3}$ & 100 & $\mathrm{R} \$ 27,98 / \mathrm{m}^{3}$ \\
Mais de 10 (Pública) & $\mathrm{R} \$ 13,82 / \mathrm{m}^{3}$ & $\mathrm{R} \$ 13,82 / \mathrm{m}^{3}$ & 100 & $\mathrm{R} \$ 27,64 / \mathrm{m}^{3}$ \\
\hline
\end{tabular}

Fonte: CAGEPA (2021).

\subsection{Aumento dos custos e tarifas}

Para a realização deste estudo de viabilidade econômica, considerou-se que a tarifa de água e os custos de operação irão aumentar de acordo com a taxa de inflação média projetada. Esse parâmetro foi calculado através da média anual do IPCA acumulado ao longo dos últimos noves anos. O valor médio encontrado foi de 5,61 \% ao ano, conforme exposto na Tabela 3.

Tabela 3 - Taxa média anual do IPCA dos últimos nove anos no Brasil.

\begin{tabular}{c|ccccccccc|c}
\hline Anos & 2012 & 2013 & 2014 & 2015 & 2016 & 2017 & 2018 & 2019 & 2020 & Média \\
\hline Selic (\%) & 5,84 & 5,91 & 6,41 & 10,67 & 6,29 & 2,95 & 3,75 & 4,31 & 4,52 & 5,61 \\
\hline
\end{tabular}

Fonte: IBGE (2021).

\subsection{Viabilidade econômica}

Considerando-se que a implantação de um determinado projeto não exige restrições em relação ao desempenho técnico, social e ambiental, faz-se necessário verificar sua viabilidade econômica. Esta pode ser avaliada através de métodos que forneçam valores de parâmetros, cujos resultados auxiliarão na tomada de decisão para a implantação ou não do projeto.

Os indicadores a serem utilizados nas análises econômicas do uso dos mictórios secos estão baseados na determinação dos custos e benefícios envolvidos ao longo do tempo para este tipo de projeto. Os empregados, para este estudo de viabilidade econômica, serão: Valor Presente Líquido (VPL), Relação Benefício/Custo (B/C), Tempo de Retorno de Capital (TRC) e Taxa Interna de Retorno (TIR).

\subsubsection{Valor Presente Líquido (VPL)}

O VPL é geralmente aplicado quando se deseja comparar várias alternativas de projetos. Este determina o valor presente de custos ou benefícios futuros descontados a uma taxa de juros apropriada. Para isso, considera-se o conceito de valor de dinheiro ao longo do tempo, uma vez em que se há a oportunidade de aplicar o dinheiro em algum tipo de 
investimento financeiro.

Para as análises econômicas deste artigo, calculou-se os VPL segundo a Equação 01.

$$
V P L=V P_{\hat{A} \text { gua }}-\left(C I+V P_{C O}\right)
$$

Em que $V P_{\text {Água }}$ é o Valor Presente (VP) do benefício da economia de água em relação ao aparelho sanitário instalado anteriormente; $C I$ são os custos de implantação do mictório seco; e $V P_{C O}$ é o VP dos custos de operação ao longo do tempo de vida útil de projeto. Para se calcular os VP de qualquer parâmetro financeiro, utiliza-se o procedimento descrito pela Equação 02.

$$
V P=\left[\frac{(1+i n f)^{n}-(1+T M A)^{n}}{(i n f-T M A)(1+T M A)^{n}}\right]\left[P_{o}(1+\text { inf })\right]
$$

Em que inf é o aumento médio anual do parâmetro, que será a inflação projetada; $n$ é o tempo de vida útil, em anos; e $P_{o}$ é o valor do parâmetro no início da implantação do projeto.

Quanto à viabilidade financeira do uso do mictório seco, deve-se avaliar o VPL da análise econômica. Quando o mesmo apresentar um saldo positivo, é porque se trata de uma instalação viável economicamente, enquanto negativo, inviável, e zero, indiferente.

\subsubsection{Relação Benefício/Custo (B/C)}

A Relação B/C é a razão de quanto se espera ganhar a cada unidade de capital investido. Esse valor é uma proporção simples entre o fluxo de caixa esperado de benefícios de um projeto e o fluxo de caixa esperado do investimento necessário para realizá-lo, conforme a Equação 03. Quando o mesmo é superior a 1, refere-se a uma situação com viabilidade econômica, enquanto, inferior a 1 , com inviabilidade, e igual a 1 , indiferente.

$$
B / C=\frac{V P_{\text {Agua }}}{C I+V P_{C o}}
$$

\subsubsection{Tempo de Retorno de Capital (TRC)}

Seguidamente, objetivou-se o cálculo dos TRC, em anos, para cada cenário adotado. O TRC é o período necessário para se zerar o VPL do projeto. Logo, utilizou-se o recurso Solver, da ferramenta Microsoft Excel, para resolver a Equação 04, gerada a partir da Equação 01, a fim de se encontrar os TRC, com a restrição de que os mesmos se situariam num intervalo de 0 a 20 anos, quando os VPL estiverem zerados.

$$
\left[\frac{(1+i n f)^{T R C}-(1+T M A)^{T R C}}{(\text { inf }-T M A)(1+T M A)^{T R C}}\right]\left[\left(\AA^{\prime} g u a_{o}-C O_{o}\right)(1+\text { inf })\right]-C I=0
$$

Em que Água $a_{o}$ é o valor financeiro anual estimado pela economia de água e $\mathrm{CO}_{o}$ são os custos anuais de operação do aparelho sanitário no início da implantação dos mictórios secos.

\subsubsection{Taxa Interna de Retorno (TIR)}

Em sequência, buscou-se calcular as TIR para cada cenário adotado. A TIR é a taxa de juros em que se zera o VPL do 
projeto. Quando a TIR é superior à TMA, significa que a instalação do mictório seco é economicamente atrativa, caso seja inferior, não seria atrativa, e caso igual, indiferente. Então, para encontrar os valores das TIR, utilizou-se o recurso Solver, da ferramenta Microsoft Excel, para forçar o zeramento dos VPL, variando-se a TMA projetada ao ano entre 0 e $550 \%$ durante esse processo. Zerados os VPL, encontram-se as TIR.

\subsection{Usos diários mínimos}

Para se determinar o número mínimo de usos diários do mictório seco para cada cenário adotado, tendo a viabilidade econômica, deve-se primeiramente relacionar esse parâmetro com os dados de Água e $\mathrm{CO}_{o}$, conforme as Equações 05 e 06 , respectivamente.

$$
\text { Água }_{o}=0,365 \times m \times Q_{E} \times \text { Taxa }_{\text {Água }}
$$

Em que $m$ é o número de usos diários do mictório seco; $Q_{E}$ é o volume, em litros, para o cenário adotado, de água economizado; e $\operatorname{Taxa}_{\hat{A} q u a}$ é a tarifa por metro cúbico de água fornecida pela concessionária local para o cenário em análise.

$$
C O_{o}=\frac{365 m}{u} \times V_{\text {Cartucho }}
$$

Em que $V_{\text {Cartucho }}$ é o valor do cartucho que acondiciona o refil do gel selante do mictório seco no momento da implantação desse aparelho sanitário; e $u$ é o número de usos máximos que o cartucho suporta tendo funcionabilidade adequada, que, neste caso, é de 7.500.

Em seguida, utilizou-se novamente o recurso Solver, da ferramenta Microsoft Excel, para resolver a Equação 07, gerada a partir da Equação 04, a fim de se encontrar o número mínimo $m$ de usos diários do mictório seco para que haja a viabilidade econômica.

$$
365 m\left[\frac{(1+i n f)^{T V U}-(1+T M A)^{T V U}}{(\text { inf }-T M A)(1+T M A)^{T V U}}\right]\left[\left(\frac{Q_{E} \times T_{\text {Taxa }}}{1000}-\frac{V_{\text {Cartucho }}}{u}\right)(1+\text { inf })\right]-C I=0
$$

Em que TVU é o tempo de vida útil de projeto, que, para este estudo, é de 20 anos. Para esta análise, igualou-se o valor do TRC a esse parâmetro, pois quando se tem essa situação, os benefícios e custos irão se igualar ao final do tempo de vida útil de projeto.

\section{Resultados e Discussão}

Neste item, apresentam-se os resultados das categorias residencial, comercial, industrial e pública para os três cenários abordados neste estudo de viabilidade econômica.

\subsection{Categoria residencial}

Para a análise econômica da categoria residencial, encontrou-se a quantidade de usos diários na qual o investimento se torna viável e, também, os valores de VPL, Relação B/C, TRC e TIR em função do número de usos diários. Além disso, em cada cenário, foram obtidos esses indicadores para as três tarifações cobradas pela concessionária de abastecimento de água. 


\subsubsection{Cenário 1}

No cenário 1, em que a economia de água é de 1 litro por uso do aparelho sanitário, não foi realizado o estudo de viabilidade econômica para esta categoria, pois não se considerou a existência do mictório convencional em residências. Isso se deve ao fato de não ser comum a presença deste nessa tipologia de edificação.

\subsubsection{Cenário 2}

No cenário 2, em que há a substituição da bacia sanitária de acionamento duplo pelo mictório seco, economizando-se 3 litros de água por uso, encontrou-se o número mínimo de usos diários para que haja a viabilidade econômica, conforme dados da Tabela 4.

Tabela 4 - Ocorrência da viabilidade econômica, no cenário 2, para a categoria residencial.

\begin{tabular}{c|ccc}
\hline Padrão da tarifa residencial & Popular & Média & Alta \\
\hline Tarifa de água por m $\mathbf{m}^{3}$ & $\mathrm{R} \$ 9,43$ & $\mathrm{R} \$ 13,13$ & $\mathrm{R} \$ 18,78$ \\
Custos de implantação & $\mathrm{R} \$ 985,55$ & $\mathrm{R} \$ 985,55$ & $\mathrm{R} \$ 985,55$ \\
Número de usos diários mínimo & Não houve & 19,1 & 6,9 \\
Número de usuários & Não houve & 4,8 & 1,7 \\
VP dos Custos de operação & Não houve & $\mathrm{R} \$ 3.027,35$ & $\mathrm{R} \$ 1.100,01$ \\
VP dos Custos totais & Não houve & $\mathrm{R} \$ 4.012,90$ & $\mathrm{R} \$ 2.085,56$ \\
VP da economia de água & Não houve & $\mathrm{R} \$ 4.012,90$ & $\mathrm{R} \$ 2.085,56$ \\
\hline
\end{tabular}

Fonte: Autores (2022).

Para a tarifa residencial de padrão popular, não se constatou nenhuma possibilidade de viabilidade econômica do uso de mictórios secos para este cenário. Isso acontece porque, a cada 7.500 usos dessa peça sanitária, economiza-se $22,5 \mathrm{~m}^{3} \mathrm{de}$ água, equivalente a $\mathrm{R} \$ 212,18$ de cobrança pela concessionária de abastecimento de água, valor esse inferior ao preço do cartucho que acondiciona o refil do gel selante, que deve ser trocado nessa mesma quantidade de ciclos.

Na Tabela 4, observa-se que, na tarifa residencial de padrão médio, o investimento é viável para valores a partir de 20 usos diários. Apesar do resultado positivo, é provável que, na prática, não haja viabilidade econômica, pois seriam necessários ao menos 5 usuários utilizando esse aparelho sanitário diariamente em uma residência. Nesse caso, os indicadores econômicos seriam R \$ 48,31 de VPL, 1,012 de Relação B/C, 18,73 anos de TRC e 9,52 \% de TIR de projeto.

Ainda na mesma tabela, para a tarifação de padrão alto, o mictório seco se torna viável economicamente a partir de 7 usos diários, ou seja, para uma residência composta por dois ou mais usuários, constata-se a viabilidade econômica. Para uma situação de 2 usuários utilizando o aparelho sanitário quatro vezes ao dia, os indicadores econômicos seriam R 152,57 de VPL, 1,068 de Relação B/C, 16,48 anos de TRC e 10,68 \% de TIR de projeto. Logo, observa-se que os resultados deste padrão tarifário foram melhores em relação a aquele, pois a tarifa cobrada, pela concessionária de abastecimento de água, do primeiro é mais barata.

Nos Gráficos 1, 2, 3 e 4, mostram-se as relações dos VPL, B/C, TRC e TIR de projeto em função do número de usos diários do mictório seco, respectivamente, para o cenário 2, da categoria residencial. 
Research, Society and Development, v. 11, n. 2, e43311225877, 2022

(CC BY 4.0) | ISSN 2525-3409 | DOI: http://dx.doi.org/10.33448/rsd-v11i2.25877

Gráfico 1 - Relação entre o VPL e os usos diários, para o cenário 2, da categoria residencial.

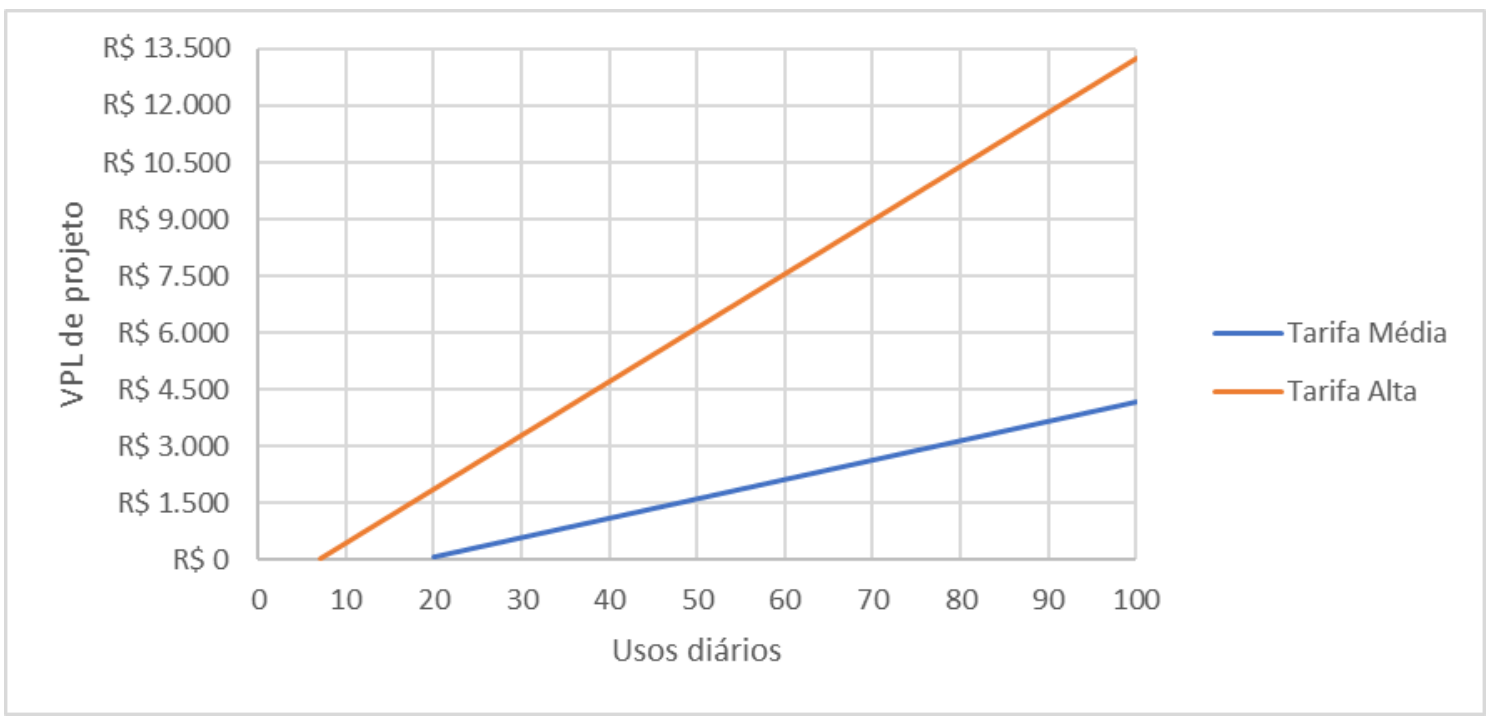

Fonte: Autores (2022).

Gráfico 2 - Relação entre o B/C e os usos diários, para o cenário 2, da categoria residencial.

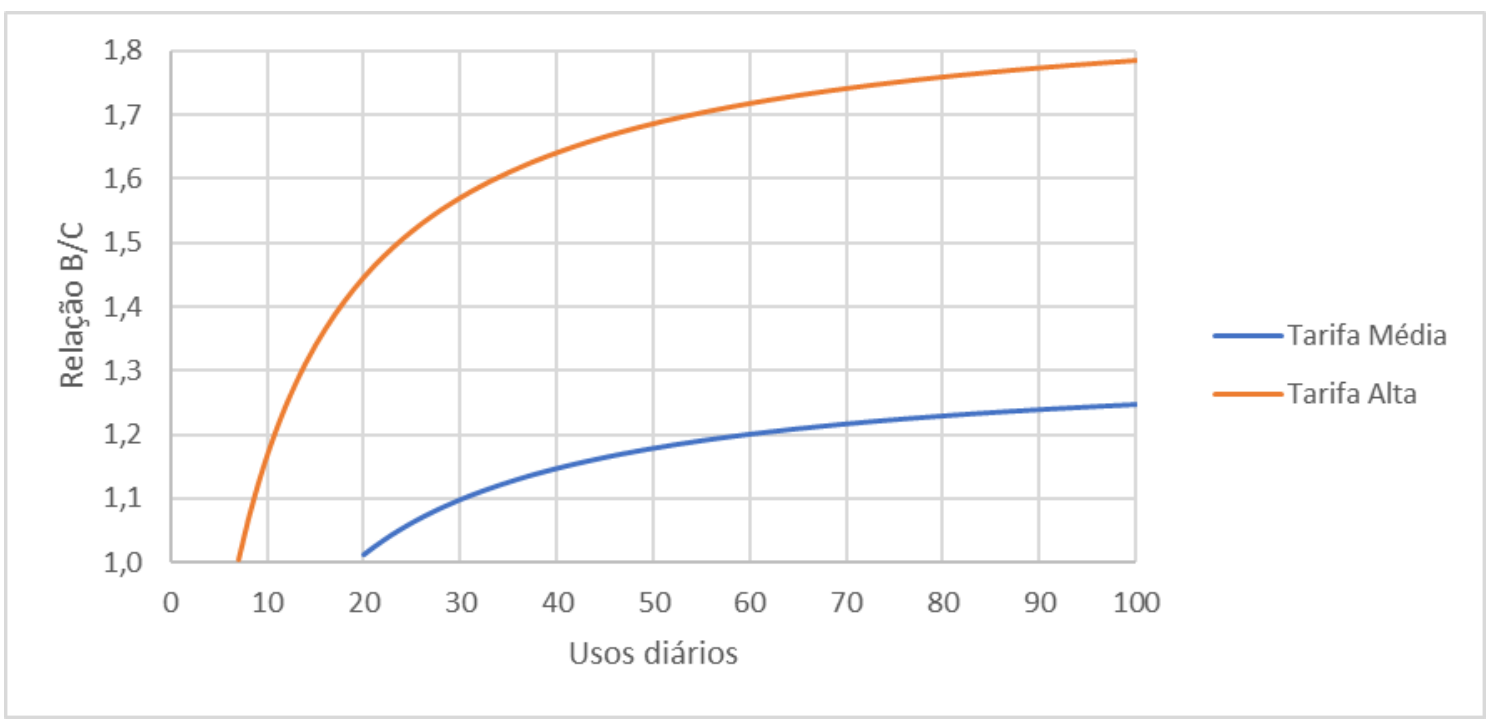

Fonte: Autores (2022). 
Research, Society and Development, v. 11, n. 2, e43311225877, 2022

(CC BY 4.0) | ISSN 2525-3409 | DOI: http://dx.doi.org/10.33448/rsd-v11i2.25877

Gráfico 3 - Relação entre o TRC e os usos diários, para o cenário 2, da categoria residencial.

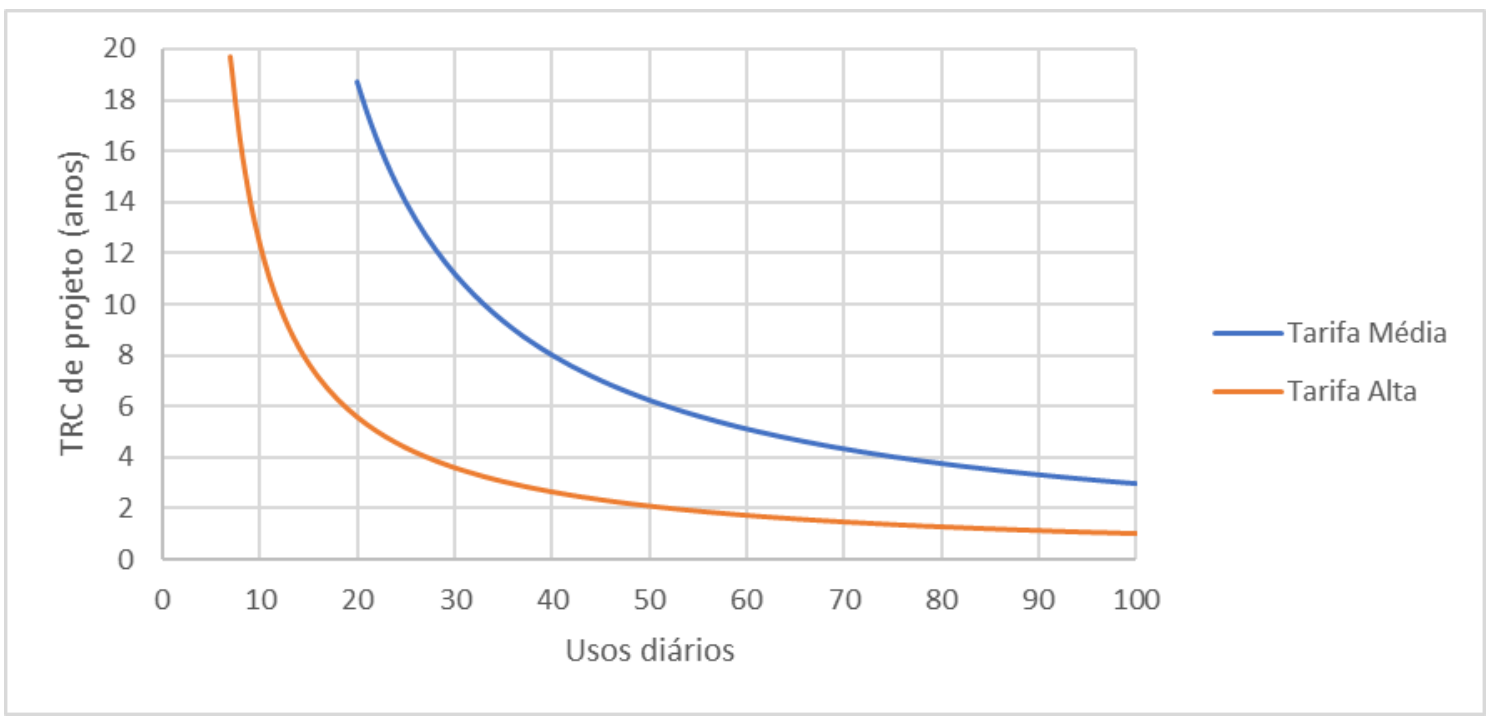

Fonte: Autores (2022).

Gráfico 4 - Relação entre a TIR e os usos diários, para o cenário 2, da categoria residencial.

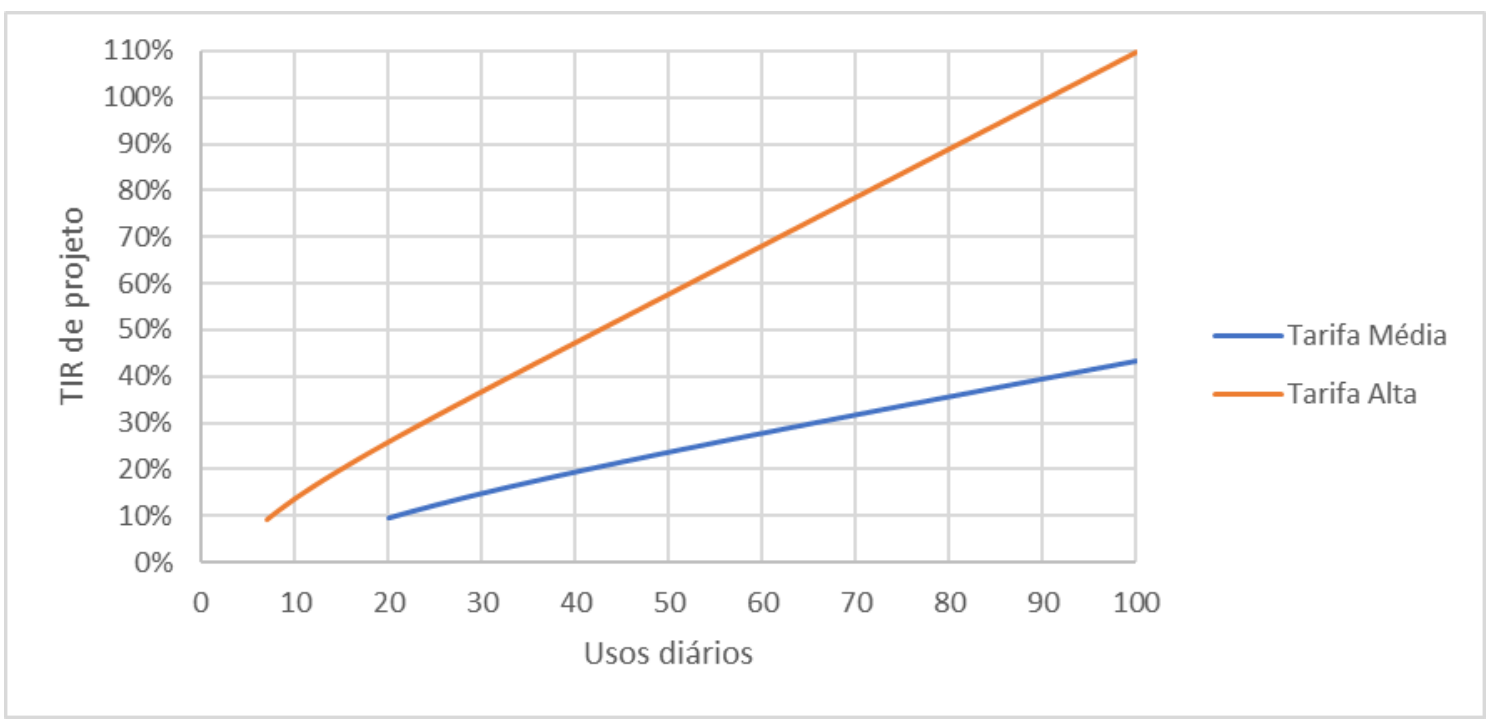

Fonte: Autores (2022).

\subsubsection{Cenário 3}

No cenário 3, em que há a substituição da bacia sanitária de acionamento único pelo mictório seco, economizando-se 6 litros de água por uso, encontrou-se o número mínimo de usos diários para que haja a viabilidade econômica, conforme dados da Tabela 5. 
Research, Society and Development, v. 11, n. 2, e43311225877, 2022

(CC BY 4.0) | ISSN 2525-3409 | DOI: http://dx.doi.org/10.33448/rsd-v11i2.25877

Tabela 5 - Ocorrência da viabilidade econômica, no cenário 3, para a categoria residencial.

\begin{tabular}{c|ccc}
\hline Padrão da tarifa residencial & Popular & Média & Alta \\
\hline Tarifa de água por m $\mathbf{m}^{3}$ & $\mathrm{R} \$ 9,43$ & $\mathrm{R} \$ 13,13$ & $\mathrm{R} \$ 18,78$ \\
Custos de implantação & $\mathrm{R} \$ 985,55$ & $\mathrm{R} \$ 985,55$ & $\mathrm{R} \$ 985,55$ \\
Número de usos diários mínimo & 6,9 & 3,8 & 2,2 \\
Número de usuários & 1,7 & 0,9 & 0,6 \\
VP dos Custos de operação & $\mathrm{R} \$ 1.090,18$ & $\mathrm{R} \$ 596,91$ & $\mathrm{R} \$ 353,00$ \\
VP dos Custos totais & $\mathrm{R} \$ 2.075,73$ & $\mathrm{R} \$ 1.582,46$ & $\mathrm{R} \$ 1.338,55$ \\
VP da economia de água & $\mathrm{R} \$ 2.075,73$ & $\mathrm{R} \$ 1.582,46$ & $\mathrm{R} \$ 1.338,55$ \\
\hline
\end{tabular}

Fonte: Autores (2022).

Nos Gráficos 5, 6, 7 e 8, mostram-se as relações dos VPL, B/C, TRC e TIR em função dos usos diários do mictório seco, respectivamente, para o cenário 3 , da categoria residencial.

Gráfico 5 - Relação entre o VPL e os usos diários, para o cenário 3, da categoria residencial.

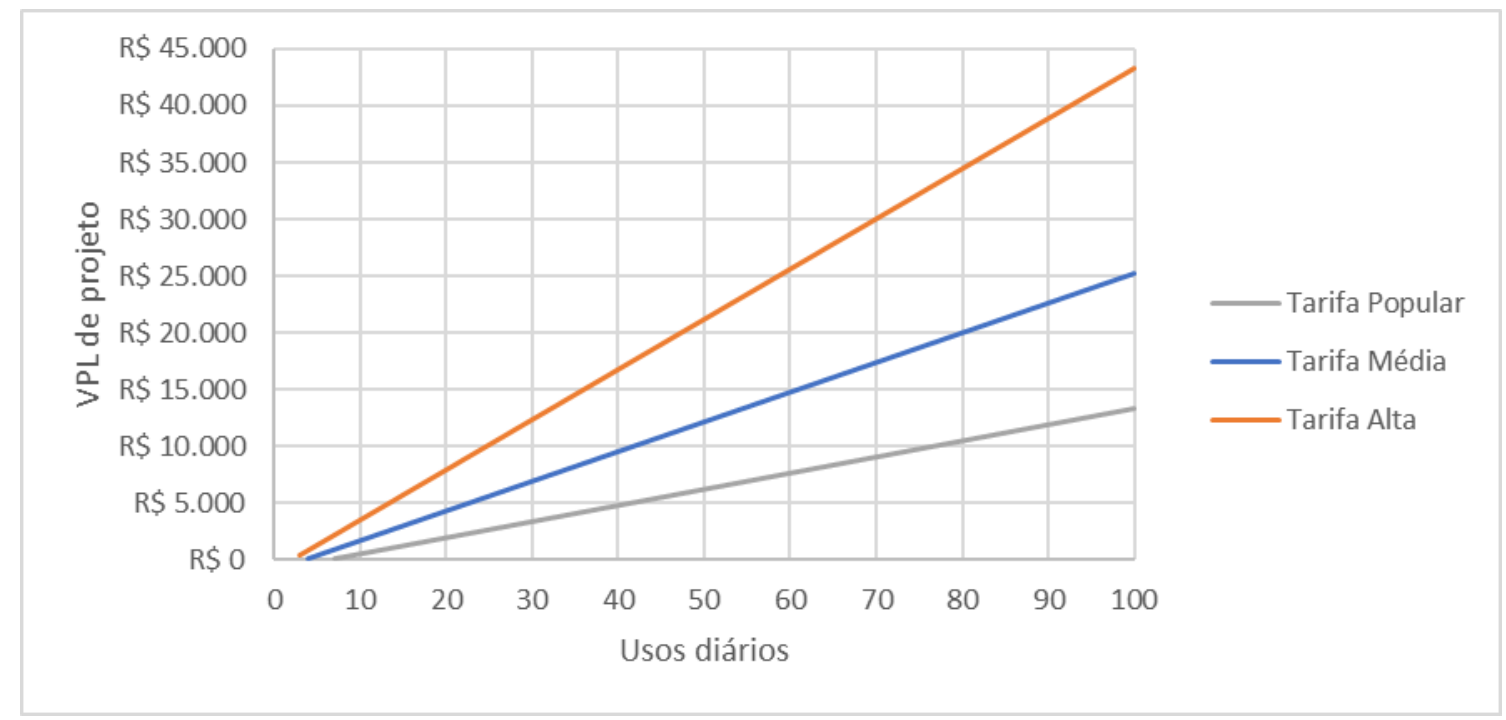

Fonte: Autores (2022).

Gráfico 6 - Relação entre o B/C e os usos diários, para o cenário 3, da categoria residencial.

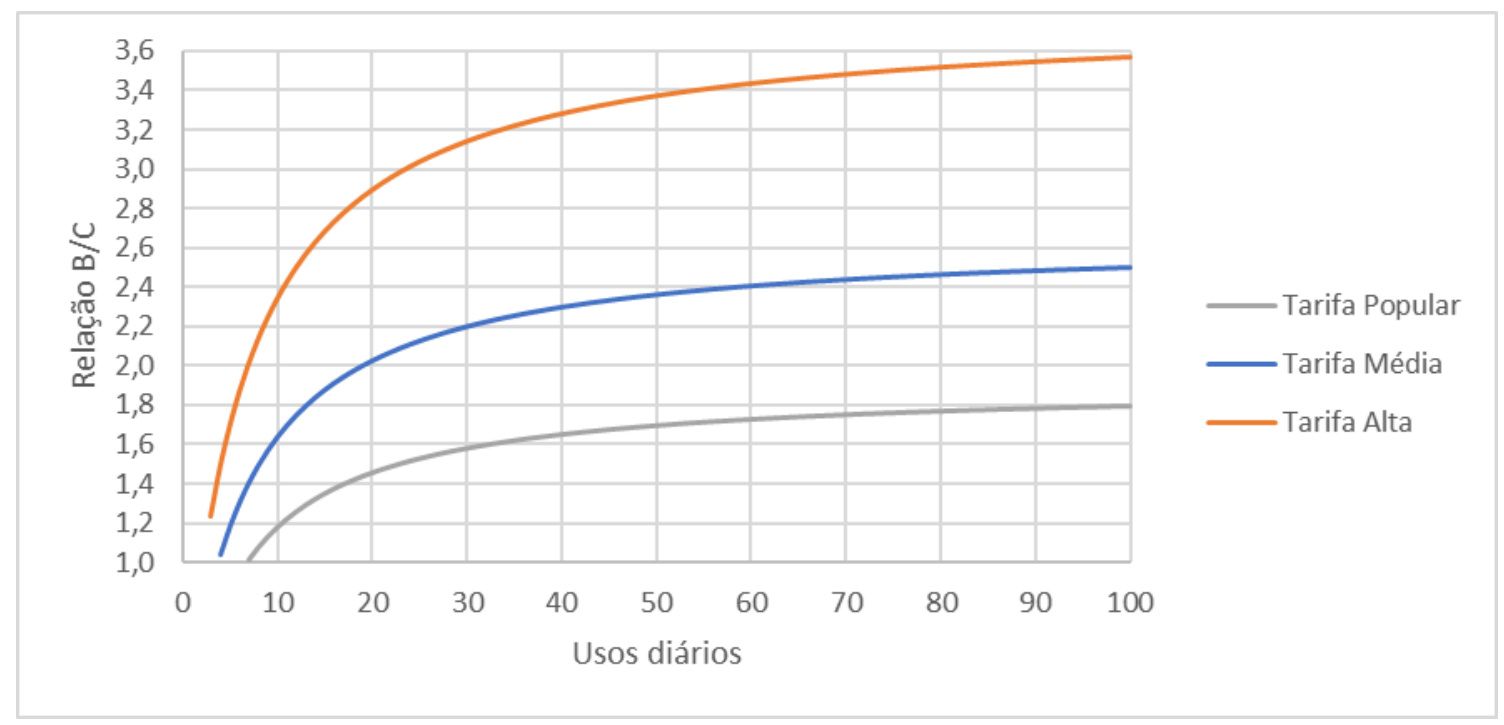

Fonte: Autores (2022). 
Research, Society and Development, v. 11, n. 2, e43311225877, 2022

(CC BY 4.0) | ISSN 2525-3409 | DOI: http://dx.doi.org/10.33448/rsd-v11i2.25877

Gráfico 7 - Relação entre o TRC e os usos diários, para o cenário 3, da categoria residencial.

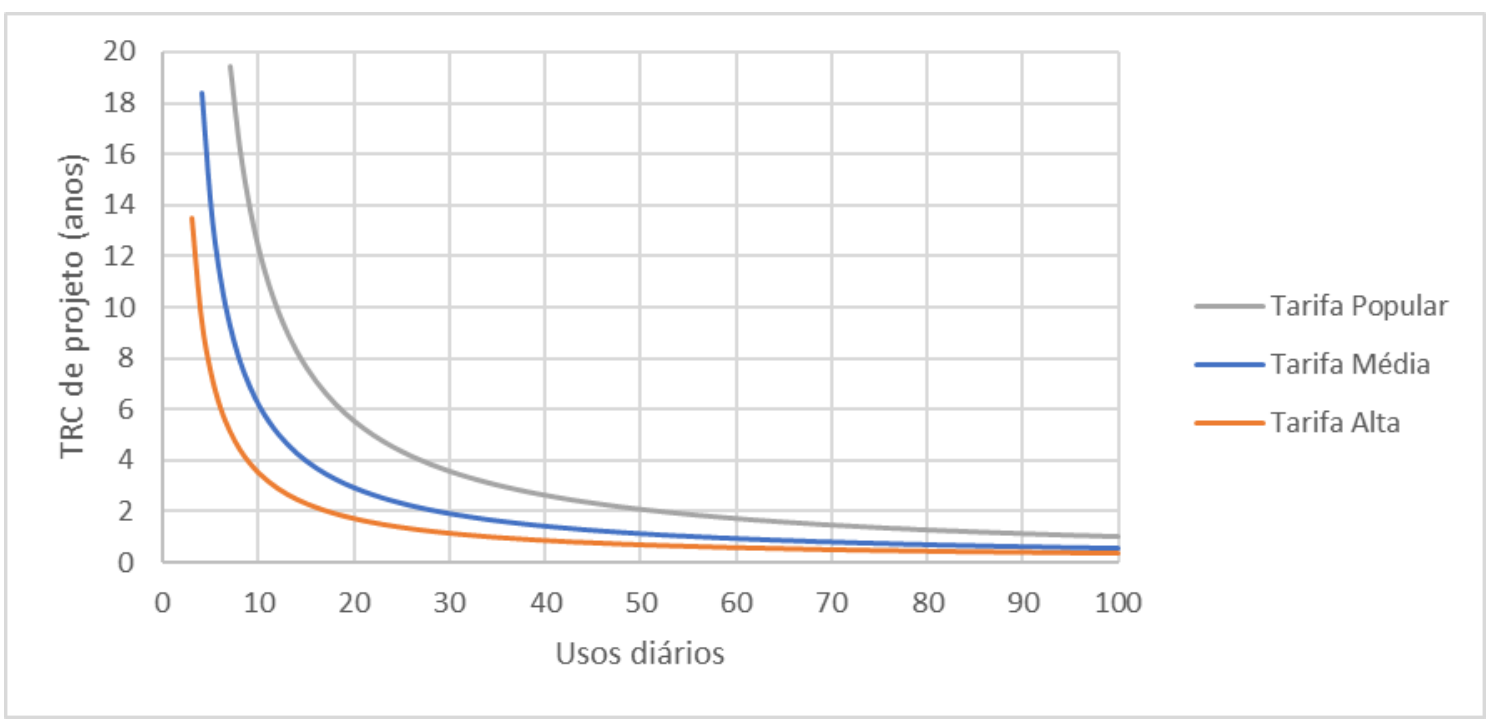

Fonte: Autores (2022).

Gráfico 8 - Relação entre a TIR e os usos diários, para o cenário 3, da categoria residencial.

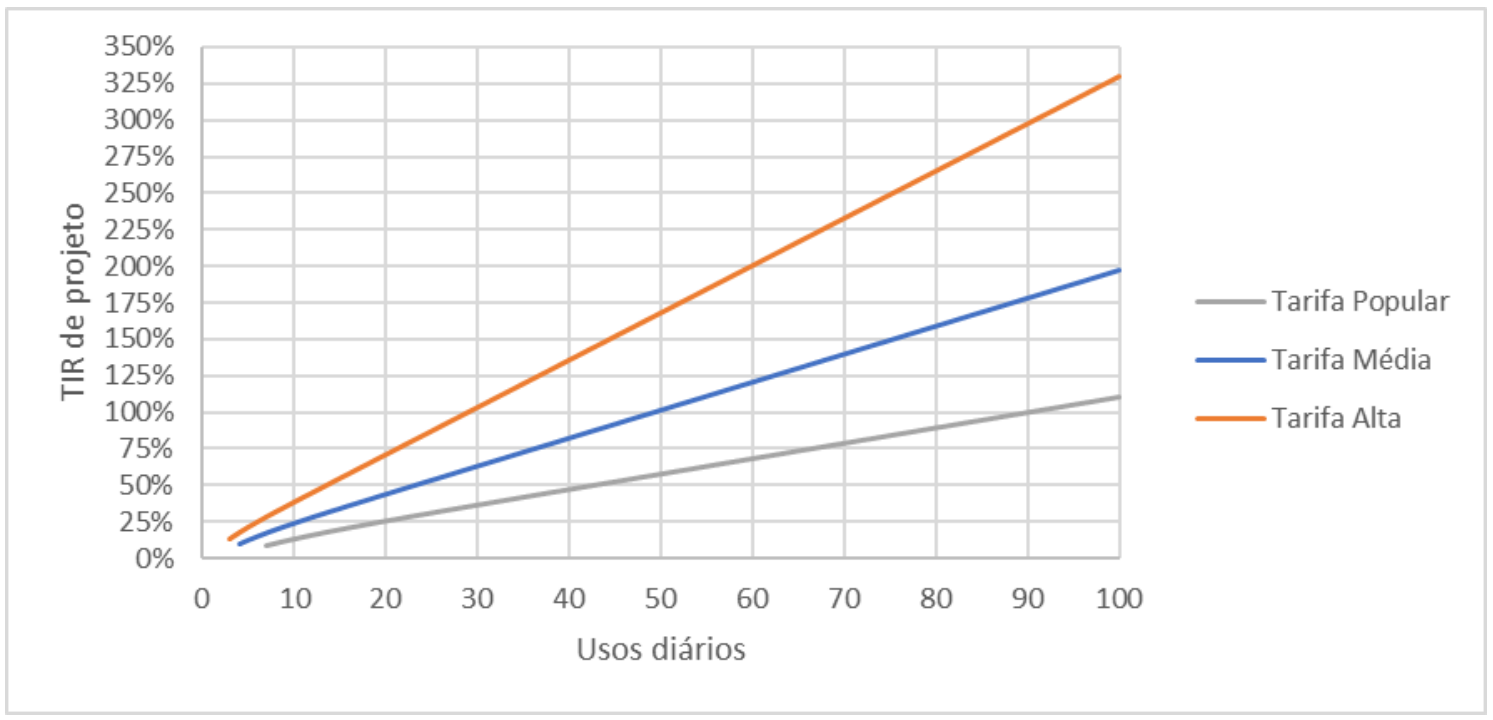

Fonte: Autores (2022).

Diferentemente do cenário 2, para a tarifa residencial de padrão popular, constatou-se a possibilidade de viabilidade econômica, a partir de 7 usos diários do mictório seco, permitindo-se afirmar que uma residência composta por dois ou mais usuários é viável economicamente para este cenário 3. Os indicadores econômicos para uma residência com dois usuários seriam R \$ 162,83 de VPL, 1,072 de Relação B/C, 16,28 anos de TRC e 10,79 \% de TIR.

$\mathrm{Na}$ Tabela 5, observa-se que, na tarifa de padrão médio, o investimento é viável para valores a partir de 4 usos diários, equivalente à presença de um único usuário na residência. Nesse caso, os indicadores econômicos seriam R \$63,14 de VPL, 1,039 de Relação B/C, 18,37 anos de TRC e 9,69 \% de TIR. Já para a tarifação de padrão alto, o mictório seco se torna viável economicamente a partir de 3 usos diários, ou seja, para uma residência em que há a presença de ao menos um usuário, constata-se a viabilidade econômica. Para uma situação de um único usuário utilizando o aparelho sanitário quatro vezes ao dia, os indicadores econômicos seriam R \$344,40 de VPL, 1,236 de Relação B/C, 13,51 anos de TRC e 12,68 \% de TIR. 


\subsection{Demais categorias}

Neste item, apresentam-se os resultados das análises econômicas realizadas para as categorias comercial, industrial e pública, avaliando-se, para todos os três cenários, os mesmos indicadores analisados anteriormente. Destaca-se que, para as categorias não residenciais, não se analisou a variável número de usuários, pois a rotatividade e a frequência de pessoas nesses ambientes variam constantemente, analisando-se apenas o número de usos diários.

\subsubsection{Cenário 1}

No cenário 1, em que a economia de água é de 1,0 litro por uso do aparelho sanitário, não se constatou nenhuma possibilidade de viabilidade econômica na instalação dos mictórios secos para as categorias comercial, industrial e pública. Isso ocorre porque o preço do cartucho que acondiciona o refil do gel selante é de $\mathrm{R} \$ 222,87$ e deve ser substituído a cada 7.500 usos do mictório seco. Nessa situação, evita-se um gasto de 7,5 $\mathrm{m}^{3}$ de água e, para que não haja perdas financeiras com a economia de água, a tarifa cobrada, pela concessionária local de abastecimento de água, deveria ser de, no mínimo, R\$ $29,72 / \mathrm{m}^{3}$, superior aos valores cobrados atualmente para as três categorias analisadas no item 3.2.

\subsubsection{Cenário 2}

Nos Gráficos 9, 10, 11 e 12, mostram-se as relações dos VPL, B/C, TRC e TIR de projeto em função do número de usos diários do mictório seco, respectivamente, para o cenário 2, das categorias comercial, industrial e pública.

Gráfico 9 - Relação entre o VPL e os usos diários, para o cenário 2, das demais categorias.

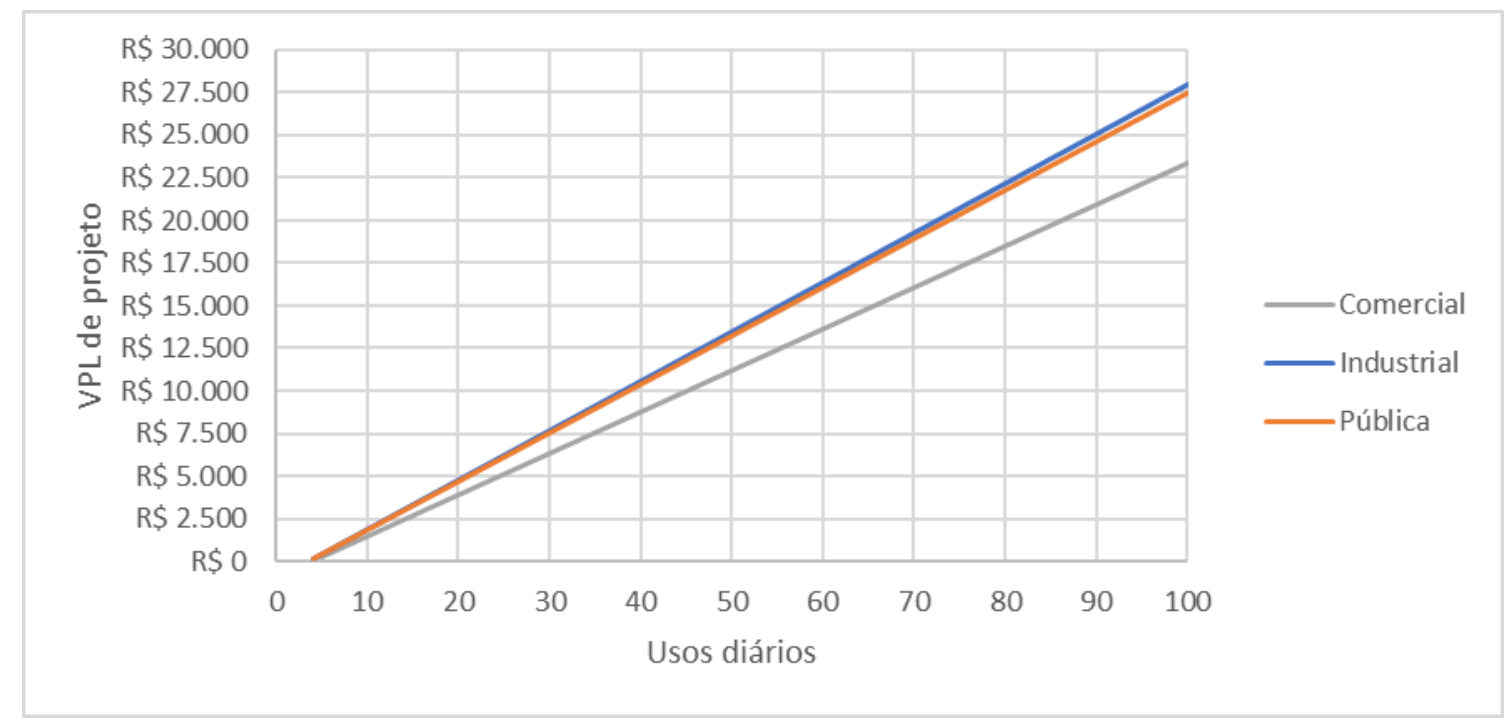

Fonte: Autores (2022). 
Research, Society and Development, v. 11, n. 2, e43311225877, 2022

(CC BY 4.0) | ISSN 2525-3409 | DOI: http://dx.doi.org/10.33448/rsd-v11i2.25877

Gráfico 10 - Relação entre o B/C e os usos diários, para o cenário 2, das demais categorias.

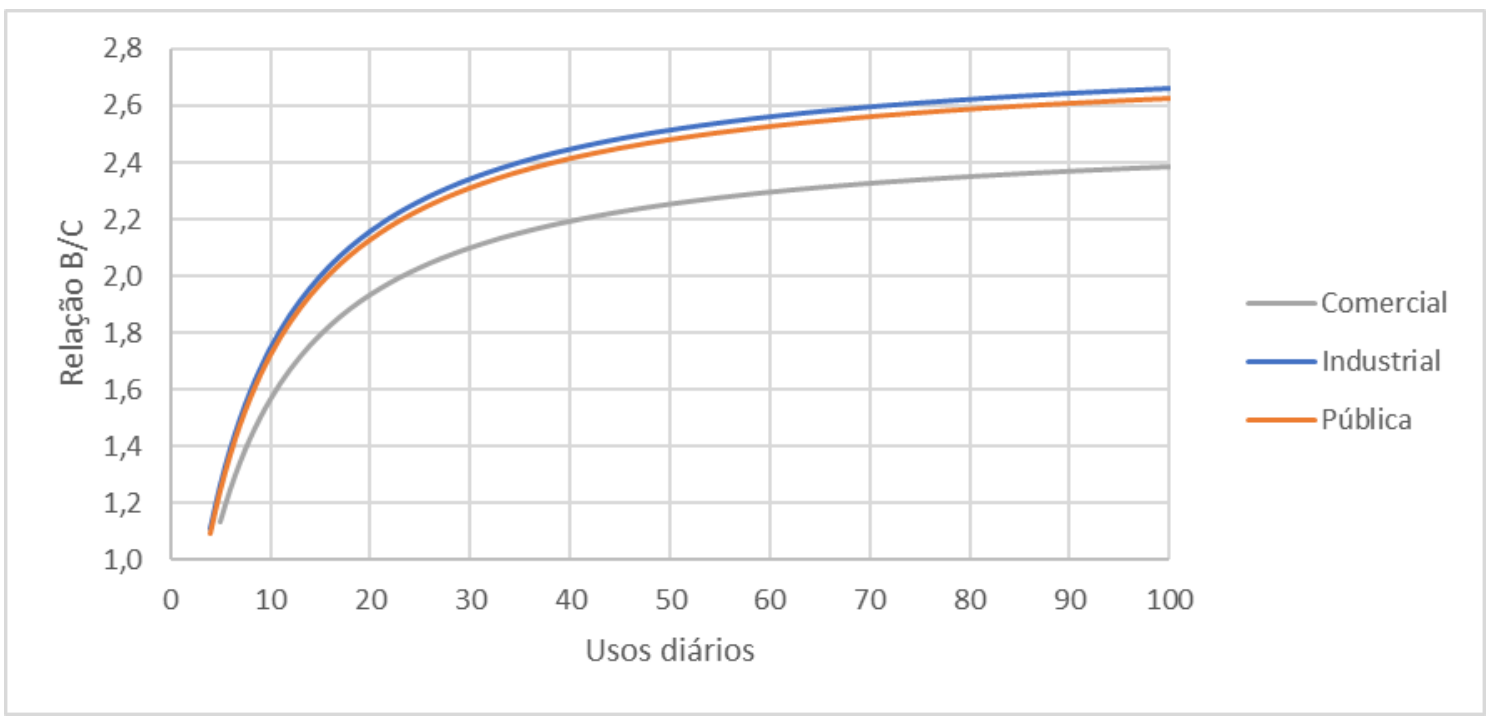

Fonte: Autores (2022).

Gráfico 11 - Relação entre o TRC e os usos diários, para o cenário 2, das demais categorias.

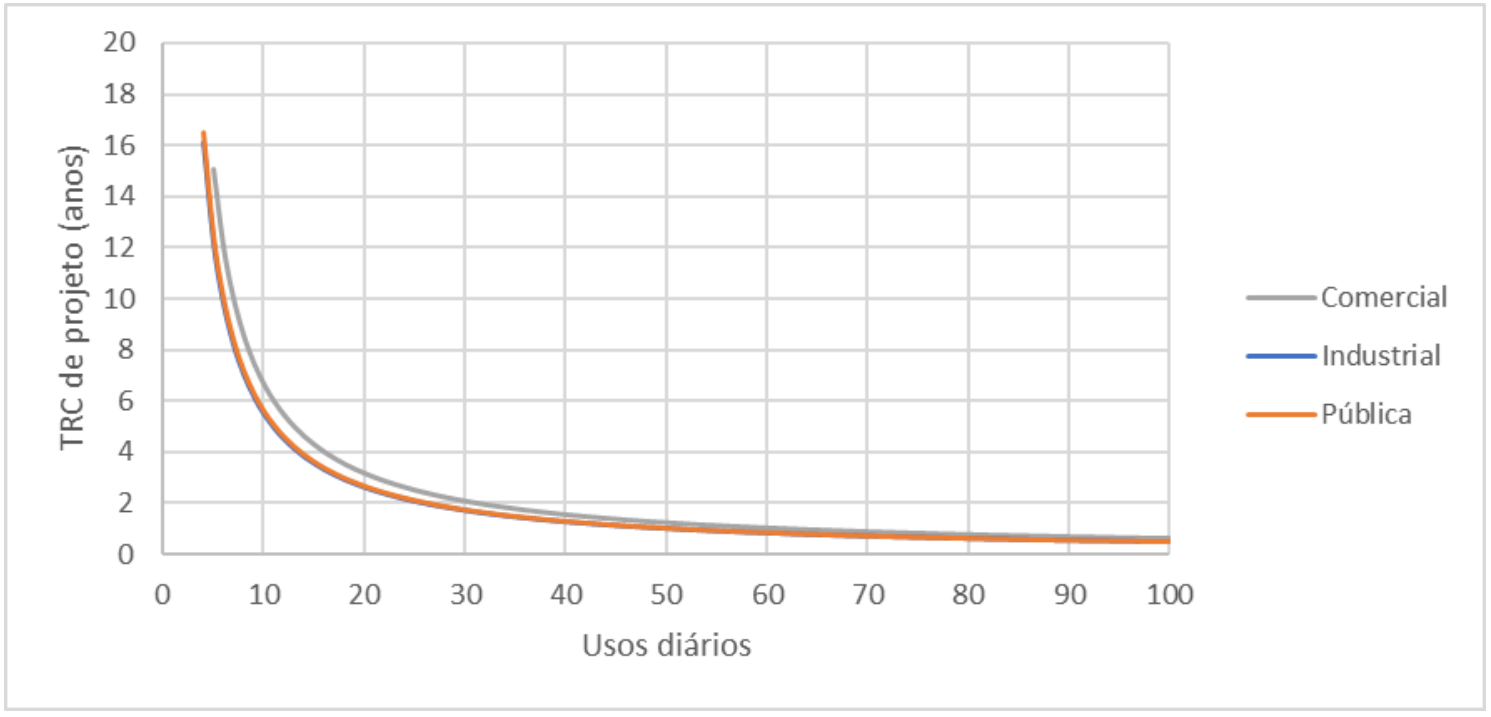

Fonte: Autores (2022). 
Gráfico 12 - Relação entre a TIR e os usos diários, para o cenário 2, das demais categorias.

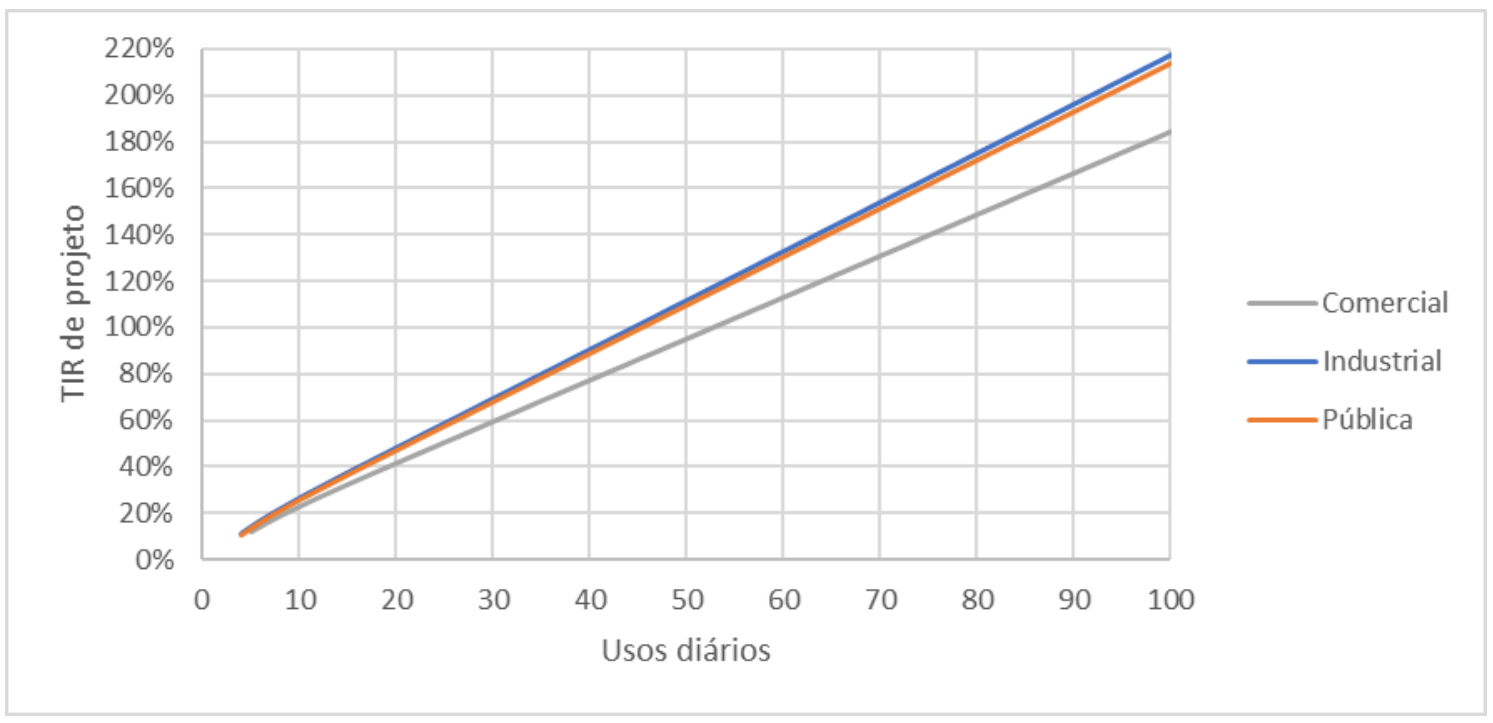

Fonte: Autores (2022).

No cenário 2, em que há a substituição da bacia sanitária de acionamento duplo pelo mictório seco, economizando-se 3 litros de água por uso, encontrou-se o número mínimo de usos diários para que haja a viabilidade econômica para as categorias comercial, industrial e pública, conforme dados da Tabela 6.

Tabela 6 - Ocorrência da viabilidade econômica, no cenário 2, para as demais categorias.

\begin{tabular}{c|ccc}
\hline Tipos de categorias & Comercial & Industrial & Pública \\
\hline Tarifa de água por $\mathrm{m}^{3}$ & $\mathrm{R} \$ 25,12$ & $\mathrm{R} \$ 27,98$ & $\mathrm{R} \$ 27,64$ \\
Custos de implantação & $\mathrm{R} \$ 985,55$ & $\mathrm{R} \$ 985,55$ & $\mathrm{R} \$ 985,55$ \\
Número de usos diários mínimo & 4,0 & 3,4 & 3,5 \\
VP dos Custos de operação & $\mathrm{R} \$ 641,63$ & $\mathrm{R} \$ 540,10$ & $\mathrm{R} \$ 550,46$ \\
VP dos Custos totais & $\mathrm{R} \$ 1.627,18$ & $\mathrm{R} \$ 1.525,65$ & $\mathrm{R} \$ 1.536,01$ \\
VP da economia de água & $\mathrm{R} \$ 1.627,18$ & $\mathrm{R} \$ 1.525,65$ & $\mathrm{R} \$ 1.536,01$ \\
\hline
\end{tabular}

Fonte: Autores (2022).

Na Tabela 6, observa-se que, para a categoria comercial, o investimento é viável para valores a partir de 5 usos diários, com indicadores econômicos equivalentes a R \$ 233,94 de VPL, 1,131 de Relação B/C, 15,07 anos de TRC e 11,54 \% de TIR. Já para a categoria industrial, o mictório seco teria viabilidade econômica a partir de 4 usos diários, com R \$173,43 de VPL, 1,107 de Relação B/C, 16,09 anos de TRC e 10,90 \% de TIR. Também, para a categoria pública, tem-se 4 usos diários mínimos para que o investimento seja viável economicamente, com R \$151,63 de VPL, 1,094 de Relação B/C, 16,49 anos de TRC e 10,66 \% de TIR. Logo, verifica-se que os resultados para a categoria industrial foram os melhores, enquanto que, os da comercial, foram os menos viáveis. Isso se deve ao fato de que a cobrança tarifária, pela concessionária de abastecimento de água, para a primeira ser a maior e, para a segunda, a menor.

\subsubsection{Cenário 3}

Neste cenário, em que há a substituição da bacia sanitária de acionamento único pelo mictório seco, economizando-se 6 litros de água por uso, encontrou-se o número mínimo de usos diários para que haja a viabilidade econômica para as categorias comercial, industrial e pública, conforme dados da Tabela 7.

Na Tabela 7, observa-se que, em todas as categorias analisadas, a substituição das bacias sanitárias de acionamento único pelos mictórios secos é viável economicamente a partir de 2 usos diários. Utilizando-se esse valor como referência, a 
categoria comercial registrou um VPL de R\$ 307,62, uma Relação B/C de 1,236, um TRC de 13,99 anos e uma TIR de 12,31 $\%$, enquanto a industrial, $\mathrm{R} \$ 491,01,1,377,11,88$ anos e 14,12 \%, e a pública, $\mathrm{R} \$ 469,21,1,360$, 12,10 anos e 13,91 \%, respectivamente. Similarmente ao cenário 2, constatou-se também que os melhores indicadores econômicos foram os da categoria industrial, seguido pelos setores público e comercial de modo respectivo.

Gráfico 13 - Relação entre o VPL e os usos diários, para o cenário 3, das demais categorias.

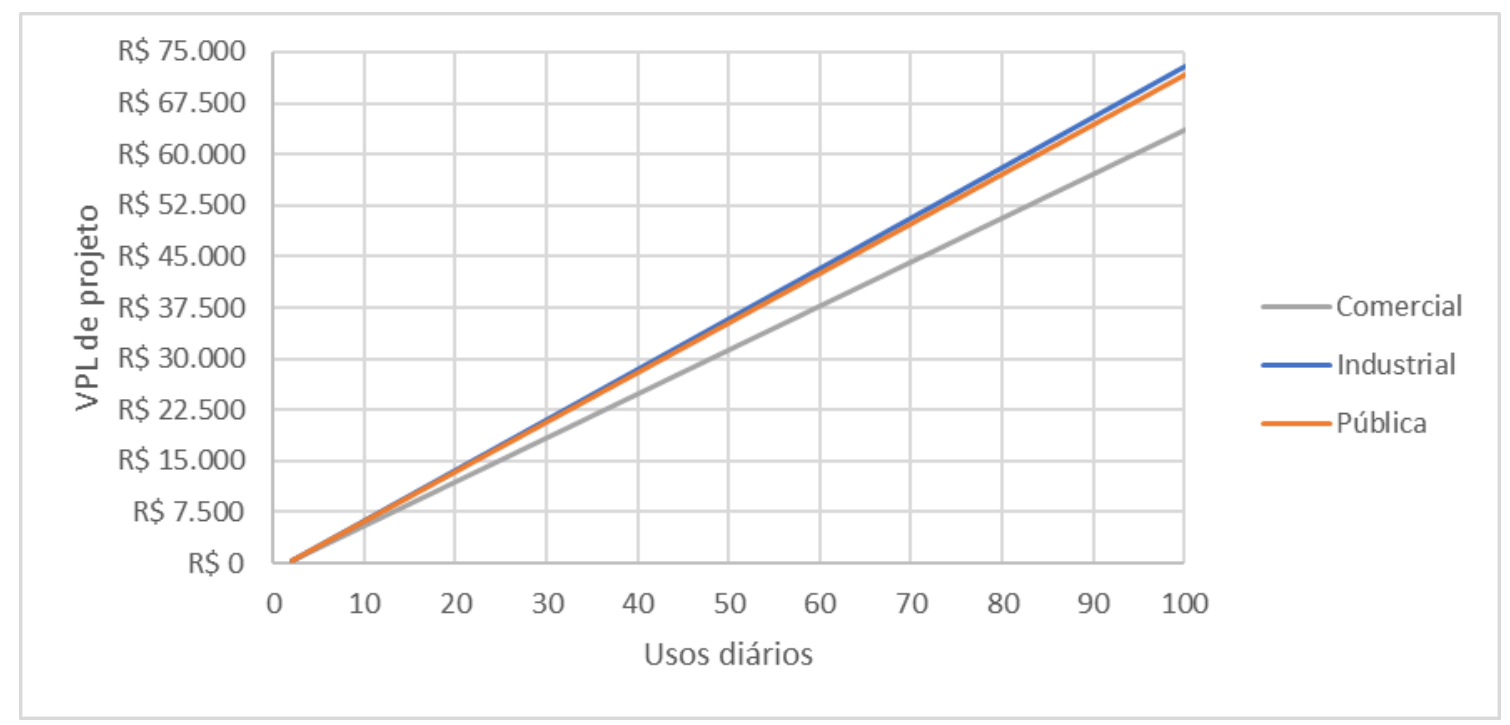

Fonte: Autores (2022).

Gráfico 14 - Relação entre o B/C e os usos diários, para o cenário 3, das demais categorias.

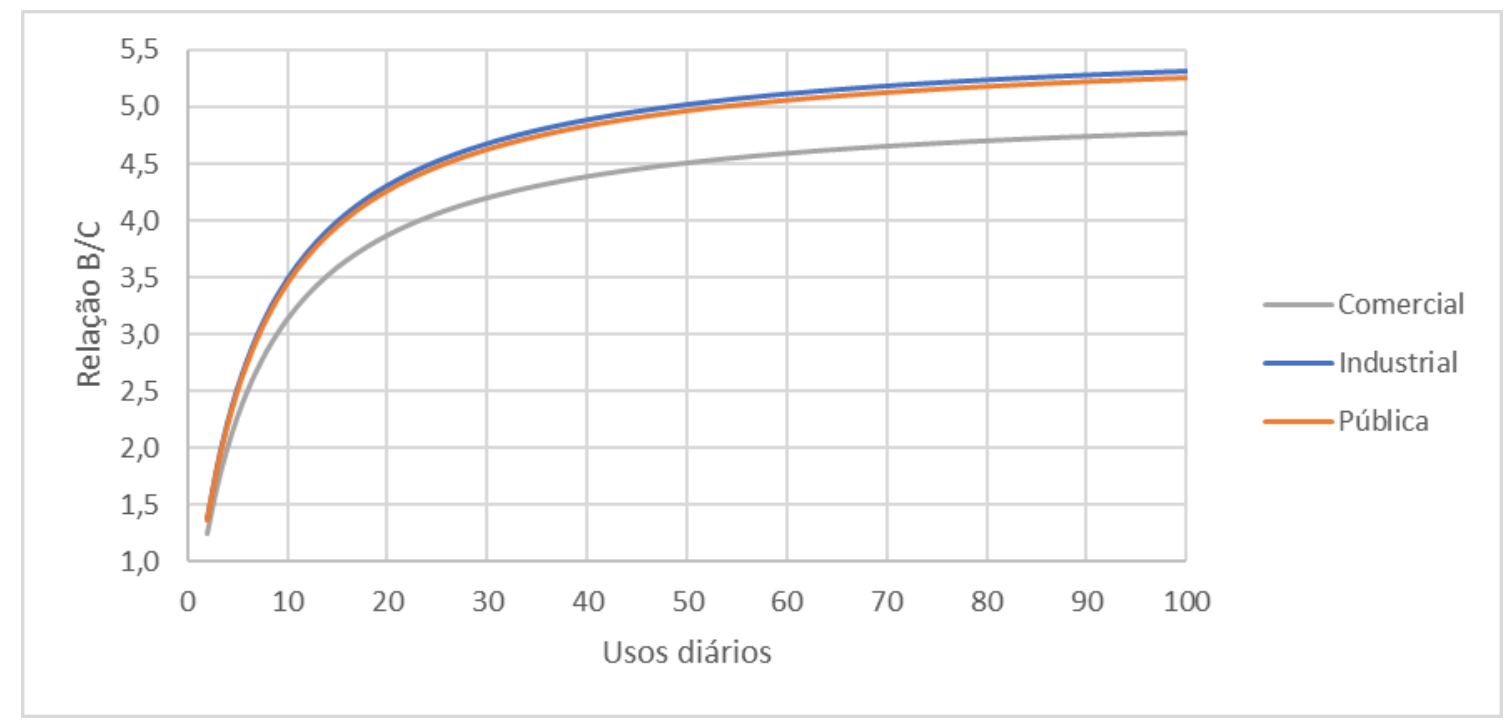

Fonte: Autores (2022). 
Research, Society and Development, v. 11, n. 2, e43311225877, 2022

(CC BY 4.0) | ISSN 2525-3409 | DOI: http://dx.doi.org/10.33448/rsd-v11i2.25877

Gráfico 15 - Relação entre o TRC e os usos diários, para o cenário 3, das demais categorias.

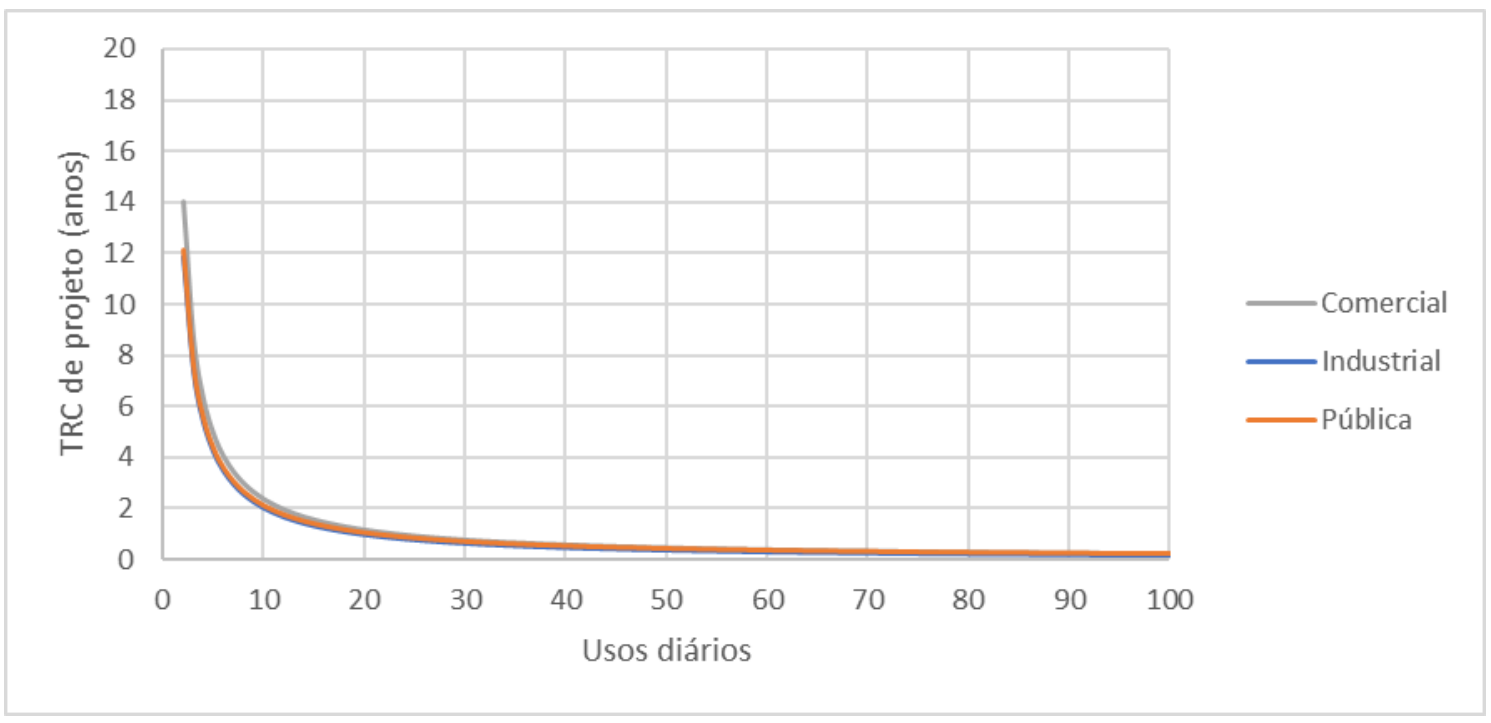

Fonte: Autores (2022).

Gráfico 16 - Relação entre a TIR e os usos diários, para o cenário 3, das demais categorias.

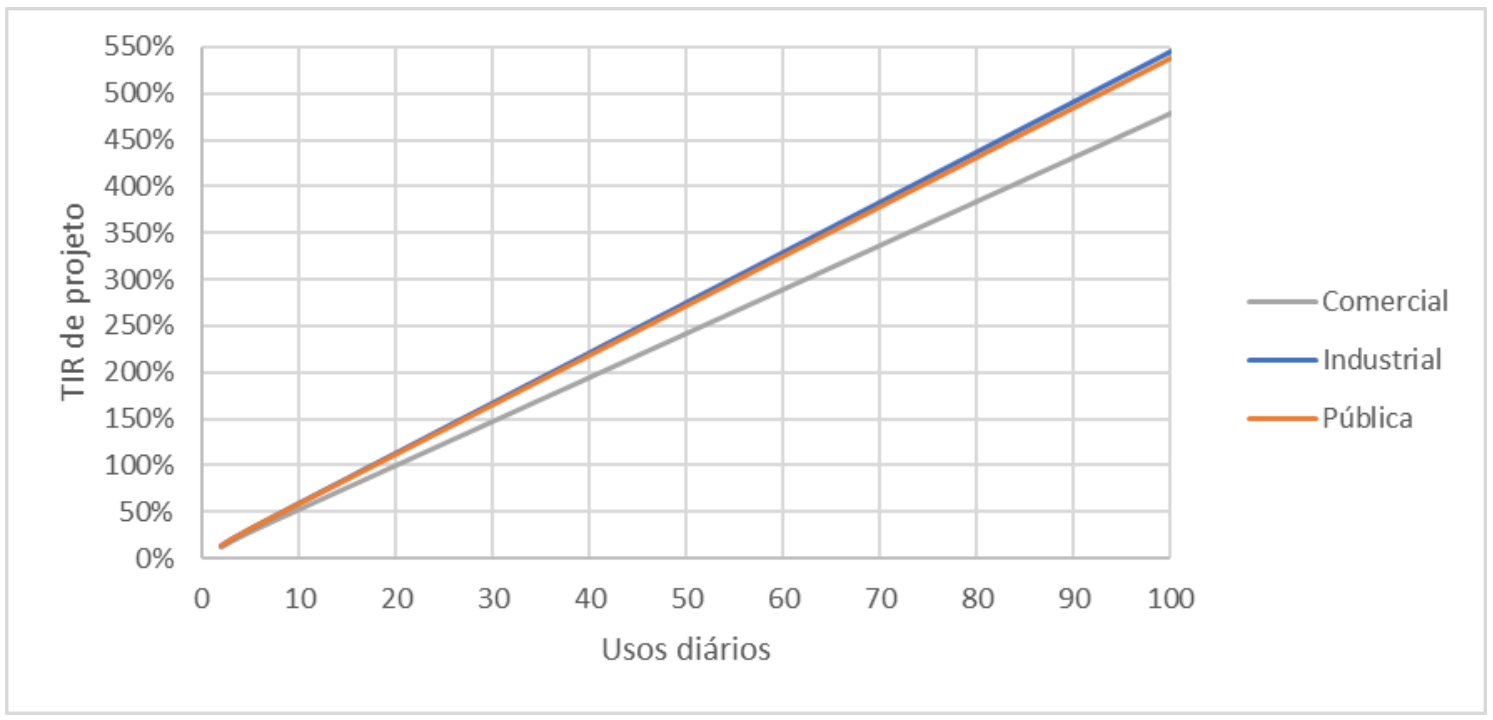

Fonte: Autores (2022).

Nos Gráficos 13, 14, 15, 16, mostram-se as relações dos VPL, B/C, TRC e TIR de projeto em função do número de usos diários do mictório seco, respectivamente, para o cenário 3.

Tabela 7 - Ocorrência da viabilidade econômica, no cenário 3, para as demais categorias.

\begin{tabular}{c|ccc}
\hline Tipos de categorias & Comercial & Industrial & Pública \\
\hline Tarifa de água por m $\mathrm{m}^{3}$ & $\mathrm{R} \$ 25,12$ & $\mathrm{R} \$ 27,98$ & $\mathrm{R} \$ 27,64$ \\
Custos de implantação & $\mathrm{R} \$ 985,55$ & $\mathrm{R} \$ 985,55$ & $\mathrm{R} \$ 985,55$ \\
Número de usos diários mínimo & 1,5 & 1,3 & 1,4 \\
VP dos Custos de operação & $\mathrm{R} \$ 242,03$ & $\mathrm{R} \$ 211,97$ & $\mathrm{R} \$ 215,15$ \\
VP dos Custos totais & $\mathrm{R} \$ 1.227,58$ & $\mathrm{R} \$ 1.197,52$ & $\mathrm{R} \$ 1.200,70$ \\
VP da economia de água & $\mathrm{R} \$ 1.227,58$ & $\mathrm{R} \$ 1.197,52$ & $\mathrm{R} \$ 1.200,70$ \\
\hline
\end{tabular}

Fonte: Autores (2022). 


\section{Conclusão}

Constatou-se que a substituição da bacia sanitária de acionamento único pelo mictório seco é viável economicamente para qualquer cenário analisado neste artigo, enquanto a troca da bacia sanitária de acionamento duplo só não é viável do ponto de vista econômico para residências em que há a cobrança da tarifa popular e média. Já para o cenário 1, em que há a mudança dos mictórios convencionais para os mictórios secos, não foi registrada nenhuma possibilidade de viabilidade econômica, pois o valor economizado referente ao não uso da água é inferior ao preço de mercado do cartucho que acondiciona o refil do gel selante para uma mesma quantidade de usos dos aparelhos sanitários.

Na categoria residencial, para o cenário 2, conclui-se que a substituição da bacia sanitária de acionamento duplo pelo mictório seco é viável economicamente a partir de 20 usos diários para a tarifa média e 7 para a alta. Apesar da viabilidade numérica da tarifação intermediária, considerou-se que a mesma é pouco provável, pois seria necessário a presença de 5 usuários em uma única residência. Já para o cenário 3, foi verificada a viabilidade econômica para usos diários a partir de 7, 4 e 3 para as tarifas popular, média e alta, respectivamente. Nas categorias comercial, industrial e pública, para o cenário 2, os mictórios secos apresentaram-se viáveis economicamente a partir de 5, 4 e 4 usos diários, e para o cenário 3, 2, 2 e 2 usos diários, respectivamente.

Para edificações classificadas nas categorias comercial, industrial e pública, onde há um grande fluxo de pessoas circulando nos ambientes e, consequentemente, uma maior utilização dos aparelhos sanitários, a substituição da bacia sanitária pelo mictório seco, além de poupar água, traz benefícios econômicos consideráveis a esses tipos de empreendimentos. Medidas como essa, em larga escala, contribuem para o uso mais racional da água, reduzindo os efeitos da escassez hídrica e proporcionando um desenvolvimento mais sustentável.

Além disso, observa-se ainda que uma adequada funcionabilidade dos mictórios secos depende de uma manutenção contínua desses aparelhos sanitários, realizando-se, a cada 7.500 usos, a troca do cartucho que acondiciona o refil do gel selante. Entretanto, nem sempre o valor economizado de água será superior a esse custo de manutenção, tornando, assim, alguns dos cenários inviáveis do ponto de vista econômico. Com isso, para que haja a possibilidade de viabilidade financeira, o valor mínimo cobrado pela água deveria ser de $\mathrm{R} \$ 29,72$, $\mathrm{R} \$ 9,91$ e $\mathrm{R} \$ 4,95$ por metro cúbico consumido para os cenários 1,2 e 3, respectivamente.

Por fim, cabe-se destacar que a concessionária local de abastecimento de água adota uma estrutura tarifária na qual a economia ligada à rede distribuidora paga uma taxa mínima de consumo, sendo adicionado novos valores a essa taxa para um excedente acima de 10 metros cúbicos consumidos mensalmente. Com isso, conclui-se que a viabilidade econômica só poderá ocorrer para economias ligadas à rede distribuidora cujo consumo seja superior a $10 \mathrm{~m}^{3}$ mensais. Portanto, para pequenas edificações ou locais com pouca circulação de pessoas, talvez não seja viável economicamente substituir os aparelhos sanitários por mictórios secos.

Sugere-se para trabalhos futuros, pesquisas com o intuito de diminuir os custos de fabricação, bem como reduzir custos de operação dos mictórios secos, visando tornar a alternativa viável para uma maior quantidade de cenários possíveis.

\section{Referências}

ADVFN - Advanced Financial Network. (2021). Taxa SELIC. https://br.advfn.co m/indicadores/taxa-selic.

Bastos, M. M. A. (2013). Opções tecnológicas para conservação de água e redução de esgoto doméstico em um edifício residencial dotado de sistema de reuso de água cinza. Projeto de Graduação (Graduação em Engenharia Ambiental) - Universidade Federal do Espírito Santo, Vitória.

Bristow, G., McClure, J. D. \& Fisher, D. (2006). Waterless urinals: Features, benefits, and applications. Journal of Green Building, 1(1), 55-62.

CAGEPA - Companhia de Água e Esgotos da Paraíba. (2021). Estrutura Tarifária. http://agenciavirtual.cagepa.pb.gov.br/gsan/exibirConsultarEstruturaTarif ariaPortalCagepaAction.do 
Research, Society and Development, v. 11, n. 2, e43311225877, 2022

Carvalho, M. V. (2021). Análise econômica das opções de biometanização, compostagem e reciclagem para tratamento de Resíduos Sólidos Urbanos no Brasil. Dissertação de Mestrado (Programa de Pós-Graduação em Engenharia Civil e Ambiental) - Universidade Federal da Paraíba, João Pessoa.

Chipako, T. L. \& Randall, D. G. (2019). Urinals for water savings and nutrient recovery: a feasibility study. Water SA, 45(2), $266-277$.

Fernandes, R. O., Silva, N. J. M., Silva, W. O. (2013). Economia financeira gerada pelo uso de duas tecnologias de conservação da água em uma edificação pública no Cariri Cearense. In: Anais... XX Simpósio Brasileiro de Recursos Hídricos: ABRH, 2013, Bento Gonçalves-RS.

Gil, A. C. (2007). Métodos e técnicas de pesquisa social. (5a ed.), Atlas.

Gomes, H. P. (2019). Abastecimento de água. João Pessoa: LENHS / UFPB.

Gonçalves, R. F. (2006). Uso racional de água em edificações. Associação Brasileira de Engenharia Sanitária e Ambiental (ABES).

Hafner, A. V. (2007). Conservação e reuso de água em edificações - experiências nacionais e internacionais. Dissertação de Mestrado - Universidade Federal do Rio de Janeiro.

IBGE - Instituto Brasileiro de Geografia e Estatística. (2021). Índice Nacional de Preços ao Consumidor Amplo - IPCA. https://www.ibge.gov.br/estatisticas/economicas /precos-e-custos/9256-indice-nacional-de-precos-ao-consumidor-amplo.html?=\&t=o-que-e

Jimenez Cisneros, B. E., Oki, T., Arnell, N. W., Benito, G., Cogley, J. G., D€Oll, P., Jiang, T. \& Mwakalila, S. S. (2014). Freshwater resources. Intergovernmental panel on climate change (IPCC), climate change 2014: impacts, adaptation, and vulnerability. In: Contribution of Working Group II to the Fifth Assessment Report of the IPCC. Cambridge University Press, Cambridge/New York, UK/USA, p. 229-269.

Lopes, M. Z. (2016). Ações de o uso racional da água em edificações públicas. Trabalho de Conclusão de Curso (Graduação em Engenharia Civil) Universidade Federal da Paraíba, João Pessoa.

Marins, N. \& Moura, D. A. (2015). Análise da utilização de equipamento economizador na promoção do uso racional de água em prédio público. In: Anais... VI Congresso Brasileiro de Gestão Ambiental Porto Alegre - RS.

Medeiros, D. L., Kiperstok, A. C., Nascimento, F. R. A., Cohim, E. H. B. \& Kiperstok, A. (2021). Human urine management in resource-based sanitation: water-energy-nutrient nexus, energy demand and economic performance. Sustainable Production and Consumption, 26, 988-998.

Richardson, R. J. (2017). Pesquisa social: métodos e técnicas. (4a ed.), Atlas.

São Paulo. Companhia de Saneamento Básico do Estado de São Paulo (SABESP). (2009). Manual de gerenciamento para controladores de consumo de água. São Paulo.

Shmidt, W. (2004). Caracterização e formulação de parâmetros para avaliação de mictórios - o caso do mictório sem água. Dissertação de Mestrado (Escola Politécnica) - Universidade de São Paulo, São Paulo.

Sampaio, L. S., Vieira, Z. C., Silva Júnior, C. G., Santos, D. K. A. S. \& Santos, D. L. (2019). Utilização de mictórios economizadores como forma de reduzir o consumo de água em escolas. In: Anais... XII Encontro de Recursos Hídricos em Sergipe, 2019, Aracaju - SE.

Silva, G. S. (2004). Programas permanentes de uso racional de água em campi universitários: O Programa de Uso Racional de Água da Universidade de São Paulo. Dissertação de Mestrado (Escola Politécnica) - Universidade de São Paulo, São Paulo.

Venancio, D. F. V., Santos, R. M., Cassaro, S. \& Pierro, P. C. C. (2015). A crise hídrica e sua contextualização mundial. Enciclopédia Biosfera, 11(22), 1-13. 